\title{
Utilização do bagaço de malte como alimentação animal: uma alternativa para o pequeno produtor
}

\author{
Use of malt bagasse as animal feeding: an alternative for the small \\ producer \\ 1 Jéssica Motta Carvalho mottajssica@yahoo.com.br \\ 2 Ana Caroline da Silva Simões \\ 2 Mabelle Biancardi Oliveira de Medeiros \\ 3 Alba Regina Pereira Rodrigues
}

1 Graduanda do curso de Engenharia de Alimentos. Centro Federal de Educação Tecnológica Celso Suckow da Fonseca (CEFET/RJ).

2 Departamento de Engenharia de alimentos - Fenomênos de Transporte. Centro Federal de Educação Tecnológica Celso Suckow da Fonseca (CEFET/RJ).

3 Departamento de Engenharia de Alimentos - Tecnologia de Alimentos. Centro Federal de Educação Tecnológica Celso Suckow da Fonseca (CEFET/RJ).

\section{Resumo}

O consumo de leite e de carne bovina vem aumentando, o que se deve ao elevado consumo interno e pelas exportações. No entanto, as áreas de pastagens vêm diminuindo a cada ano, o que ocasionaria uma falta de alimentação para o gado. Um outro problema que se intensifica são as perdas no processo industrial ou a geração de resíduos. Em algumas indústrias, esses resíduos gerados não sofrem um reaproveitamento adequado, podendo causar problemas ambientais. Logo, a necessidade de produção de alimentos para os ruminantes e o descarte adequado para os resíduos industriais tornam-se um aliado para a solução do problema. Nesta pesquisa, utilizou-se o capim elefante da espécie capiaçu e bagaço de malte para a elaboração de silos, obtendo-se uma alternativa de alimentação de baixo custo para o pequeno produtor. Foram feitos silos do bagaço de malte seco, em diferentes proporções, $0 \%, 10 \%, 30 \%$ e $50 \%$, misturados com o capim elefante e avaliou-se as características físico-químicas do silo ao longo de 90 dias. Os silos com a mistura tiveram maior porcentagens de proteínas, quando comparados com o silo somente de capim, proporcionando, para o gado, uma alimentação de melhor qualidade. Observou-se que o período de coleta e maturação do capim elefante também influenciou na proteína bruta do capim, sendo necessário avaliar as etapas de silagem para que não existam falhas, como uma boa vedação do silo e temperatura adequada. De forma geral, a silagem de capim elefante e bagaço de malte pode ser utilizada como uma alternativa de baixo custo como alimentação animal.

Palavras-chave:

Silagem. Resíduo cervejeiro. Capim elefante.

\begin{abstract}
The consumption of milk and beef has been increasing, which is due to the high domestic consumption and exports. However, pasture areas have been decreasing every year, which would cause a lack of food for livestock. Another problem that intensifies is the losses in the industrial process or the generation of waste. In some industries, this generated waste does not undergo adequate reuse, which can cause environmental problems. Therefore, the need for food production for ruminants and the proper disposal for industrial waste become an ally in solving the problem. Elephant grass of the capiaçu species and bagasse of malt was used for the elaboration of silos, obtaining a low cost of alternative food for the small producer. Silos were made from dry malt bagasse, in different proportions, 0\%, 10\%, 30\% and $50 \%$ mixed with elephant grass and evaluated the physico-chemical characteristics of the silo over 90 days. The silos with the mixture had higher percentages of proteins, when compared to the only grass silo, providing cattle with better quality feeding. It was observed that the period of collection and maturation of the grass also influences the crude protein of the grass, needing to evaluate the silage steps so that there are no flaws, such as a good silo seal and adequate temperature. In general, elephant grass silage and malt bagasse can be used as a low cost alternative as animal feeding.
\end{abstract}

\section{Keywords:}

Silage. Brewing residue. Elephant grass.

Como você deve citar?

CARVALHO, Jéssica Motta et al. Utilização do bagaço de malte como alimentação animal: uma alternativa para o pequeno produtor. Cadernos UniFOA, Volta Redonda (RJ), v. 16, n. 46, p. 1-7, ago, 2021. 


\section{INTRODUÇÃO}

De acordo com o Ministério da Agricultura, Pecuária e Abastecimento (MAPA), o consumo de leite e carne bovina vem aumentando, o que se deve ao elevado consumo interno e pelas exportações. No entanto, as áreas de pastagens vêm diminuindo a cada ano, o que ocasionaria uma falta de alimentação para o gado (BRASIL, 2007; GONÇALVES, 2009).

Quando se pensa em alimentação animal, é preciso buscar alimentos de fácil digestão. Os ruminantes necessitam de um material volumoso e nutritivo para alimentar-se de forma a suprirem todas as suas necessidades de dieta diária. O milho, sorgo e capim-elefante são as principais forrageiras usadas no processo de ensilagem (OLIVEIRA, MARTINS, 2021)

A silagem é uma saída bastante utilizada para alimentar o gado, quando a disponibilidade de pastagem é baixa. 0 processo de ensilagem tem como objetivo preservar os alimentos, produzindo ácidos orgânicos e ácido lático capazes de reduzir o $\mathrm{pH}$ e, consequentemente, inibir a proliferação de microrganismos deletérios indesejáveis. Quando o material ensilado apresenta boa fermentação, os teores de matéria seca, $\mathrm{pH}$ e carboidratos solúveis são consideravelmente de grande valia para a alimentação animal (SILVA, 2001).

Um outro problema que se intensifica são as perdas no processo industrial ou a geração de resíduos. Em algumas indústrias, esses resíduos gerados não sofrem um reaproveitamento adequado e podem causar grandes problemas ambientais dependendo da maneira pela qual são descartados (CORDEIRO, 2011). Sabe-se que a utilização de resíduos na alimentação animal possibilita um incremento na proteína bruta, energia, consumo de matéria seca e digestibilidade dos alimentos utilizados para alimentação dos ruminantes (MENEGHETTI, 2008).

Dentre os resíduos das indústrias, o bagaço de malte tem ganhado destaque devido ao grande volume gerado pelas indústrias cervejeiras anualmente (CORDEIRO, 2011). De acordo com Lopes et al. (2015), ao final do processamento da cerveja, são gerados subprodutos e o resíduo presente em maior fração, que corresponde cerca de $85 \%$ do total, é referente ao bagaço de malte, sendo esse resíduo uma alternativa para a alimentação dos ruminantes (GOMES, 2010). 0 material que sobra na peneira de filtragem constitui o resíduo úmido de cervejaria ou bagaço de cevada, podendo ser desidratado e utilizado no arraçoamento animal.

Nesse contexto, o capim-elefante (Pennisetum purpureum Schum.) apresenta excelente potencial para ensilagem, pela elevada produção de biomassa e alto valor nutritivo. No entanto, os capins tropicais caracterizam-se pelos baixos teores de matéria seca (MS) e de carboidratos solúveis, o que pode comprometer a fermentação e aumentar as perdas por efluentes. O capim-elefante cv. BRS capiaçu, recém-lançado pela Embrapa, parece ter boas características de ensilabilidade.

Esse cultivo caracteriza-se principalmente pela elevada produção de matéria seca, o que contribui significativamente para a redução nos custos de produção. Além disso, apresenta boa resistência ao estresse hídrico, elevado poder de brotação, colmos grossos, alta densidade e resistentes ao tombamento e rendimento significativo na plantação, o que pode favorecer o processo de ensilagem, com possibilidade de produção até três vezes mais, quando feita a ensilagem em conjunto a um aditivo que possui uma boa composição química, podendo chegar até 30\% de proteína bruta (PEREIRA et al., 2016).

Com a necessidade de produção de alimentos para os ruminantes e redução do descarte adequado para os resíduos industriais, procurou-se obter uma alternativa de alimentação de baixo custo para o pequeno produtor de Valença/RJ. Assim, objetivou-se ensilar o bagaço de malte seco, em diferentes 
proporções, com o capim-elefante da espécie capiaçu, avaliando-se as características físico-químicas do silo ao longo de 90 dias.

\section{METODOLOGIA}

O estudo foi realizado no Centro Federal de Educação Tecnológica Celso Suckow da Fonseca, localizado no campus Valença-RJ. Os resíduos do bagaço de malte foram doados por uma cervejaria próxima à cidade, e foram congelados e transportados até o local de análise para evitar a degradação. 0 resíduo de bagaço de malte foi desidratado na secadora do Laboratório de Origem Vegetal do campus, por 8 horas a $70^{\circ} \mathrm{C}$.

Já o capim-elefante foi colhido com a planta mais madura, visando à obtenção da melhor relação entre produção de biomassa, valor nutritivo, teor de matéria seca. 0 corte é recomendado quando as plantas atingem em média 3,5 a 4,0 m, o que ocorre próximo a 90-110 dias de idade rebrota. Utilizandose a picadeira mecânica, as plantas foram picadas em tamanho de partículas de $1-2 \mathrm{~cm}$, o que garante uma alta qualidade na silagem e uma boa compactação do material ensilado.

A silagem foi confeccionada em silos experimentais de PVC $(100 \mathrm{~mm}$ de diâmetro por $40 \mathrm{~cm}$ de altura), vedados com lonas de polietileno e foram deixados ao sol com temperatura média de $30^{\circ} \mathrm{C}$, por um período de 90 dias. Os experimentos foram realizados em triplicatas, totalizando-se 12 silos de PVC, vedados com lona, e o material utilizado seguiu as proporções de $0 \%$ (CONTROLE), $10 \%, 30 \%$ e $50 \%$ de bagaço de malte. Ao final do período de 90 dias, analisou-se o teor de proteína bruta, $\mathrm{pH}$, cinzas e umidade, realizadas de acordo com os métodos preconizados pelo Instituto Adolfo Lutz, 2005 (PADILHA et al., 2008), com delineamento feito de forma casual e aleatória. As análises foram realizadas no Laboratório de Físico-Química do CEFET/RJ, campus Valença.

\section{RESULTADOS E DISCUSSÃO}

Com o objetivo de comparação de resultados, foram feitas análises físico-químicas do capim-elefante antes do processo de ensilagem, utilizando-se o capim na sua forma in natura, obtendo-se um valor de $20,69 \%$ de umidade, $1,56 \%$ de cinzas, $8,57 \%$ de pH e 2,82 \% de proteína bruta.

De acordo com Pereira (2016), os teores de matéria seca de capim e malte devem estar entre 20 a $30 \%$. No período de estiagem, o capim não consome a quantidade de água necessária a seu pleno desenvolvimento, sendo necessários irrigação e controle do solo. Os resultados obtidos de umidade nesse experimento apresentam o valor dentro do mínimo estipulado para pós-colheita, levando-se em consideração que a colheita foi realizada no período de estiagem.

Os teores de proteína bruta ficaram abaixo do esperado, pois o mínimo para a espécie é em torno de $7 \%$. Segundo Santos (2001), um dos motivos dos valores encontrados serem baixos pode estar relacionado ao tempo de maturação dos colmos, a forma como foi coletado e triturado e também ao período do ano, já que foi coletado no período de estiagem.

As cinzas são resíduos inorgânicos que determinam os minerais totais presentes na amostra. Tem grande importância em alimentos de origem animal e vegetal, pois são utilizadas para fins nutricionais. Os valores, na literatura, para o capim-elefante ficam em média de $6,46 \%$ de cinzas (FUGIL, 2015), no entanto os resultados obtidos foram três vezes menores. Podemos utilizar algumas hipóteses para jus- 
tificar o fato ocorrido, como alterações no manuseio, composição do cultivo, idade e tempo de colheita (FUGIL, 2015).

De acordo com o trabalho realizado por Pope et al. (2018), estudo com comparações de potencial hidrogeniônico do capim-elefante in natura, está entre 3,5 a 4,5\%. 0 pH alcalino influencia a digestão na alimentação dos ruminantes, pois quanto mais próximo da neutralidade, permite o bom desenvolvimento das bactérias fibrolíticas. Já o pH elevado (ácido), está suscetível ao crescimento microbiano, podendo haver problemas com aparecimento de fungos no processo de ensilagem. Visto que o valor encontrado 8,57 neste trabalho encontra-se dentro do indicado para digestão dos ruminantes, pode-se dizer que o capim está apto a ser ensilado (OLIVEIRA, 2013).

Após o tempo de maturação dos silos (90 dias), foram feitas as análises físico-químicas, obtendo-se os resultados apresentados na Tabela 1.

Tabela 1: Resultados das análises físico-químicas nos silos de PVC após 90 dias de ensilagem.

\begin{tabular}{|c|c|c|c|c|c|c|}
\hline \multirow{2}{*}{$\%$ de malte } & \multicolumn{2}{|c|}{ Umidade \% } & \multicolumn{2}{|c|}{ Cinzas\% } & \multirow{2}{*}{$\mathrm{pH}$} & \multirow{2}{*}{ Proteína \% } \\
\hline & A & B & A & B & & \\
\hline $0 \%$ de malte & 20,93 & 16,69 & 1,63 & 1,67 & 9,73 & 20,57 \\
\hline $\begin{array}{l}10 \% \text { de } \\
\text { malte }\end{array}$ & 20,35 & 22,71 & 1,33 & 1,52 & 9,34 & 25,64 \\
\hline $\begin{array}{l}30 \% \text { de } \\
\text { malte }\end{array}$ & 31,34 & 32,94 & 2,14 & 2,12 & 8,43 & 31,33 \\
\hline $\begin{array}{l}50 \% \text { de } \\
\text { malte }\end{array}$ & 47,18 & 46,79 & 2,41 & 2,41 & 7,36 & 33,21 \\
\hline
\end{tabular}

Onde A e B são o número de repetições de cada análise.

Fonte: Os autores (2019)

Os silos com $0 \%$ de malte, um deles com a vedação violada, expôs todo o material contido, com aparecimento de partículas brancas que podem ser consideradas fungos, entretanto, não se pode confirmar, pois não foram realizadas análises microbiológicas. Já os outros dois silos, que não foram expostos ao ambiente, totalmente lacrados, não apresentaram nenhum tipo de mudança significativa. As amostras apresentaram aspecto molhado, embora o teor de umidade tenha sido menor que o indicado pela literatura, podendo variar de 28 e $35 \%$, valores recomendados de matéria seca para uma boa ensilagem (BARCELOS, 2018). Segundo relatos de Muck (1988), os teores ideais de matéria seca de silagens devem estar em torno de 30 a $35 \%$.

Os demais silos, com $10 \%, 30 \%$ e $50 \%$ de bagaço de malte, apresentaram aspecto úmido, partes secas e molhadas dentro dos silos de PVC. Em um estudo realizado por Diniz et al. (2018), a inclusão de coprodutos na ensilagem contribui para o aumento nos teores de matéria seca. Observou-se que houve um aumento proporcional em relação à quantidade de bagaço de malte e a umidade.

Os silos com $10 \%$ de malte apresentaram odor muito forte, característico do processo de ensilagem, aparentemente com ausência de microrganismos. Já os silos com 30\% de malte, apresentaram textura mais firme e seca que as demais e odor característico ao de fermentação. Nos silos com $50 \%$ de malte, foi possível observar visualmente partículas mofadas com presença de fungos e odor mais suave.

Os valores de pH estão associados ao conteúdo de matéria seca. Para se promover uma eficiente conservação da forragem ensilada, depende do período de incidência de luz solar durante a ensilagem 
e o conteúdo de matéria seca original do capim utilizado. De acordo com Pereira (2016), as enzimas da forrageira são capazes de promover degradação de proteínas; as proteases das plantas apresentam maior atividade, quando o pH está entre 6 e 7, e tem sua ação significativamente influenciada pela disponibilidade de água no meio. Já as enterobactérias, microrganismos presentes nos intestinos dos animais, contaminam as forragens ainda no campo, apresentam pH ótimo para desenvolvimento, por volta de 7 . Por sua vez, os clostrídios, considerados os principais microrganismos anaeróbicos que prejudicam a qualidade da silagem, contaminam as forragens na forma de esporos, iniciando seu processo logo que estabelecem condição de anaerobiose no silo. Em silagens em que o conteúdo de matéria seca são mais de $28 \%$, os clostrídios e enterobactérias geralmente são inativos, enquanto em materiais com cerca de $15 \%$ de matéria seca e pH abaixo de 4 , podem inibir totalmente seu crescimento.

Segundo Muck (1988), os valores de pH devem ser inferiores a 5, para que não ocorram fermentações indesejadas pela presença de microrganismos, o que não ocorreu nos silos com $0 \%$ e $10 \%$ de malte, observando-se teores de matéria seca entre $20-23 \%$ e pH alcalino. Os silos com $30 \%$ apresentaram teores de umidade dentro do esperado, entretanto o pH não estava conforme o indicado, o que pode ter provocado uma fermentação indesejável que explicaria o forte odor. Nos silos com $50 \%$ de malte, o teor de matéria seca se apresentou com valores superiores ao desejado. Pode-se observar que todas as amostras obtiveram $\mathrm{pH}$ alcalino, devido ao fato de a vedação feita com lona não ter sido eficaz para o processo, deixando as amostras expostas ao tempo.

Com o intuito de aumentar o potencial nutritivo da silagem, recomenda-se colheita no seu estado vegetativo, quando esta apresenta elevado teor de proteína e elevada digestibilidade. Em um estudo realizado por Ferrando (2015), a adição de bagaço de cevada aumentou linearmente o teor de proteína bruta do material ensilado, e comparado a outros aditivos, pode-se observar que o resíduo de cervejaria aumentou em até 3 vezes mais o teor nutritivo. Para que se tenha uma digestão, é necessário que ocorra fermentação ruminal e, para isso, é necessária uma dieta com teores de proteína acima de 7\%. Com isso, observa-se que todos os teores de proteína analisados nesse experimento apresentaram valores acima de $20 \%$.

Apesar das vantagens relacionadas ao uso do resíduo de bagaço de malte, sua utilização de forma indiscriminada na dieta dos ruminantes pode ser responsável por casos de acidose ruminal e laminite. Além disso, a contaminação do bagaço de malte por fungos tem sido associada a surtos bovinos e ovinos, caraterizada por síndromes termogênicas (BRUST, 2015). Dessa forma, é importante que se faça a secagem de todo o material úmido de cervejaria antes de se iniciar o processo de ensilagem, para garantir uma boa digestão, livre de patógenos.

\section{CONCLUSÃO}

A composição inicial do capim apresentou valores abaixo do esperado. Isso se dá por conta do período de colheita e maturação do capim. Geralmente, as silagens são feitas no período de estiagem e maturam até o período de seca, visto que o tempo de colheita não favoreceu as caraterísticas desejadas para o início do projeto.

Para um alto rendimento no processo de ensilagem, é importante que se atente aos fatores externos de plantio, como época em que foram cultivadas, período de colheita dos colmos, composição do material ensilado, secagem dos aditivos úmidos de cervejaria, vedação completa dos silos e proporções do material volumoso. Esses fatores são de extrema importância para que não haja falhas e contaminações durante o processo. 
Das quatro condições analisadas, as com $30 \%$ de malte apresentaram os melhores resultados, sendo uma boa escolha para o produtor rural, devido ao seu teor de proteína significativamente alto e visualmente livre de microrganismos. 0 bagaço de malte pode ser utilizado como uma fonte de alimentação para animais, devido a suas características de boa ensilabilidade, com alto teor de proteína, podendo ser uma alternativa de baixo custo para os produtores rurais, sabendo-se que o bagaço de malte é um resíduo descartado pelas indústrias cervejeiras.

\section{REFERÊNCIAS}

BARCELOS, A. F. et al. Valor nutritivo e características fermentativas da silagem de capim-elefante com diferentes proporções de casca de café. Ciências animais do Brasil, Goiânia, v.19, 1-12, 2018.

BRASIL. Ministério Da Agricultura, Pecuária e Abastecimento. Produtos para Alimentação Animal. Decreto n 6296 de 11 de dezembro de 2007. Disponível em: https://www.gov.br/agricultura/pt-br/assuntos/ insumos-agropecuarios/insumos-pecuarios/alimentacao-animal/alimentacao-animal. Acesso em: 17 mar. 2021.

BRUST, L. A. C. et al, Enfermidades em bovinos associadas ao consumo de resíduos de cervejaria. Pesquisa Veterinária Brasileira, v. 35, n. 12, p. 956-964, 2015.

CORDEIRO, L. G. Caracterização e viabilidade econômica do bagaço de malte oriundo de cervejarias para fins energéticos. 2011. Dissertação (Mestrado em Ciência e Tecnologia de Alimentos) - Universidade Federal da Paraíba, João Pessoa, PB, 2011.

DINIZ, J. et al. Teores de Nutrientes na silagem de capim elefante CV. Napier com adição de coprodutos regionais. XXII Encontro Latino Americano de Iniciação Científica, XVIII Encontro Latino Americano de Pós-Graduação e VIII Encontro de Iniciação à Docência - Universidade do Vale do Paraíba, 2018.

FERRANDO, J. K. Valor nutritivo do bagaço de cevada como aditivo em silagem de milho. Trabalho de Conclusão de Curso, Universidade Federal de Santa Catarina. Centro de Ciências Agrárias. Curso de Zootecnia, Florianópolis 2015. Disponível em: https://repositorio.ufsc.br/bitstream/handle/123456789/156645/ Josiane_2015_1.pdf?sequence=1. Acesso: 7 jun. 2020.

FUJIL, I. A. Determinação de umidade pelo método do aquecimento direto - técnica gravimétrica com emprego do calor. luni educacional. Universidade de Cuiabá - MT, UNIC. 2015. 5p.

GOMES, R. H. Utilização do bagaço de malte como ração animal. 2010. Trabalho de conclusão de curso (Graduação em Química Industrial) - Instituto Municipal de Ensino Superior de Assis - IMESA, Assis, 2010.

GONÇALVES, L. C.; BORGES, I.; FERREIRA, P. D. S. Alimentos para gado de leite. Editora FEPMVZ, 2009.

LOPES, C. R. et al. Estudo cinético de desidratação e caracterização do bagaço de malte resíduo da indústria, Congresso Brasileiro de Engenharia Química em Iniciação Científica, 2015.

MAPA - MINISTÉRIO DA AGRICULTURA, PECUÁRIA E ABASTECIMENTO. Assessoria de Gestão Estratégica (AGE). Disponível em: http://www.agricultura.gov.br/. Acesso em: 15 fev. 2019.

MENEGHETTI, C. C.; DOMINGUES, J. L. Características nutricionais e uso de subprodutos da agroindústria na alimentação de bovinos. Revista Eletrônica Nutritime, v. 5 n. 02, p. 512-536, 2008. 
MUCK, R. E. Factors influencing silage quality and other implications for management. Journal of Dairy Science, v. 71, p. 2292-3002, 1988.

OLIVEIRA, V. S.; SANTANA NETO, J. A.; VALENÇA, R. L. Características químicas e fisiológicas da fermentação ruminal de bovinos em pastejo - Revisão de literatura. Revista Científica Eletrônica de Medicina Veterinária, Ano XI, nº 20 - ISSN: 1679-7353, 2013.

OLIVEIRA, J. S.; MARTINS, C. E. Silagem: Agencia de Informação da Embrapa; disponível em: http:// www.agencia.cnptia.embrapa.br/Agencia8/AG01/arvore/AG01_306_217200392412.html\#: :text=0\%20 milho\%2C\%20o\%20sorgo\%20e,nutritivo\%20da\%20silagem\%20de\%20milho. Acesso em: 17 mar. 2021.

PADILHA, P.; MEDEIROS, M.; DUARTE, V.; FIGUEIREDO, E.; ABREU P.; ZENEBON, C. Instituto Adolfo Lutz, Métodos Físico-Químicos para Análise de Alimentos - $4^{\mathrm{a}}$ Edição e $1^{\mathrm{a}}$ Edição Digital. São Paulo, 2008. Disponível em: http://www.ial.sp.gov.br/resources/editorinplace/ial/2016_3_19/analisedealimentosial_2008. pdf?attach=true. Acesso em: 15 set. 2018.

PEREIRA, A. V.; LEDO, F. J. S.; MORENZ, M. J. F.; LEITE, J. L. B.; SANTOS, A. M. B.; MARTINS, C. E.; MACHADO, J. C. BRS Capiaçu: cultivar de capim-elefante de alto rendimento para produção de silagem. Comunicado Técnico 79 - Embrapa, 2016.

POPE. A.M, et al. Metodologias de mensuração do $\mathrm{pH}$ de silagens do capim elefante. $55^{\mathrm{a}}$ Reunião Anual da Sociedade Brasileira de Zootecnia. Goiânia-GO, 2018.

SANTOS, E. A., SILVA, D. S., QUEIROZ FILHO. J. L. Composição química do capim-elefante cv. Roxo cortado em diferentes alturas. Revista brasileira zootecnia, v. 30, n. 1, p.18-23, 2001.

SILVA, J. M. Silagem de forrageiras tropicais. Embrapa, agosto de 2001; disponível em: http://old.cnpgc. embrapa.br/publicacoes/divulga/GCD51.html. Acesso em: 17 mar. 2021. 